\title{
The Influence of Mass Basic Life Support Training on The Skills and Attitude in Undertaking Life Support Using the Method of the Faculty of Medicine, Universitas Âirlangga
}

\author{
Arie Utariani ${ }^{1}$, Teguh Sylvaranto ${ }^{1}$, April Poerwanto Basoeki ${ }^{1}$, Prananda Surya Airlangga ${ }^{1}$, Windy Ari \\ Wijaya $^{1}$, Soni Sunarso Sulistiawan ${ }^{1}$, Bambang Pujo Semedi ${ }^{1}$, Christrijogo Sumartono ${ }^{1}$, Hamzah ${ }^{1}$, \\ Kohar Hari Santoso ${ }^{1}$, Philia Setiawan ${ }^{1}$ and Eddy Rahardjo ${ }^{2}$ \\ ${ }^{I}$ Staff of Anesthesiology and Reanimation Department, Faculty of Medicine, Universitas Airlangga, Surabaya, \\ Indonesia \\ ${ }^{2}$ Professor of Anesthesiology and Reanimation, Faculty of Medicine, Universitas Airlangga, Surabaya, Indonesia \\ arie_utariani@yahoo.co.uk
}

Keywords: $\quad$ Airlangga University Method, Basic Life Support Training, Non-Medical Personnel, Skill and Attitude.

Abstract: The quality of basic life support training given by medical students to the public, using methods from the Faculty of Medicine, Airlangga University, appears to be effective. There is hope that it will affect the success rates of resuscitation by non-medical personnel. This study uses a quasi-experimental design, with total subjects of 1,378 persons. We compared the level of attitudes using a pre-post test, then linked this to the skill level in performing basic life support after training. The correlation test results show a significant relationship between attitude and skill. Basic life support training for non-medical personnel, using methods from the Faculty of Medicine at Airlangga University, enhances the level of attitude and skill of all participants.

\section{INTRODUCTION}

Cardiac arrest is one of the leading causes of death in the world, as the sudden cardiac death rate is quite high. Cardiac pulmonary resuscitation given by people nearby to the victim is a basic life support for patients who suffer a cardiac arrest. Cardiac arrest events can occur anywhere, and often no medical personnel are present at the scene. Basic life support performed less than four minutes after the incident, followed by cardiac advanced life support, will increase the rate of successful cardiac pulmonary resuscitation. The basic life support training provided by medical staff to the layman or common person is regarded as being effective, and is hoped to positively affect the result of resuscitation performed by the layman. Basic life support training has long been pioneered, and has attempted to be popularized within the community. Many other countries have already mandated basic life support training to the general public, yet this has not been implemented in Indonesia. Until now, no evidence-based data has proven the benefits and influence of basic life support training on the level of assessing the skills and attitudes of ordinary people to performing cardiopulmonary resuscitations in Indonesia. It is important that a study is carried out involving a large number of lay participants, to evaluate and assess the outcomes of such training. Good basic life support training is very important to show the effects of this on the quality of the training results provided. Evaluation should be carried out according to scientific rules. Therefore, there must be research into the effects of basic life support training for the layman, in order to assess the skill and attitude levels of the participants using methods from the faculty of medicine of Airlangga University.

\section{METHODS}

This study uses a quasi-experimental study design, and involves students from Pondok Pesantren Gontor in Kediri. Students are trained over five hours in basic life support (BLS), and their pre- and post- knowledge levels and attitudes are then 
compared (pre-post test design is then linked to the skill level of students in BLS after training). The research was conducted in Gontor Kediri Pondok Pesantren Hall on December 26, 2016, for one day. The population comprised students of Pondok Pesantren Gontor in Kediri, who fit the inclusion criteria. We excluded basic life trainee support (BLS), which is involved in the health sector, and does not follow the training activities from beginning to end. All of the students were tested for attitude levels one hour before BLS training. One hour after BLS training, we evaluated the levels of skill and attitude. A validity test and a check to see whether each participant has ever undertaken BLS were carried out; the data from the questionnaire results was then analyzed. The first analysis uses the Pearson Product Moment method. It is said to be valid if the significance is less than 0.05 and $r$ value count $>\mathrm{r}$ table, while reliability was tested with Cronbach's Alpha with a standard of more than 0.5 .

\subsection{Statistical Analysis}

The attitude level data was tested using a paired sample $\mathrm{t}$ test; knowledge data was also tested using a paired sample $t$ test; skill data had the scale ratio connected with attitude level and knowledge, which was tested using the Pearson correlation if normal distribution, and if not distributed normally, using Spearman's correlation.

\section{RESULTS}

The results of the validity test on attitude variables based on the Pearson test have a significant level of less than $0.0 \mathrm{~s}(0.702-0.810)$, and an $\mathrm{r}$ value count of more than $r$ table. With this result, all indicators of attitude stated are valid. Then, the reliability test obtained the value from Cronbach's Alpha of 0.893 . The value is greater than 0.5 , so the attitude variable is reliable.

The result of the validity test on the knowledge variable based on the Pearson test has a significant level of less than 0.05 (the $r$ value ranges from 0.221 to 0.479 ) and obtained all $r$ values from $r$ table $r$. With this result, all indicators of attitude are valid. Following this, the reliability test obtained the value from Cronbach's Alpha of 0.591. This value is more than 0.5 , and is considered to be reliable. The next stage eliminated the variable number 14 , because it has a low Pearson correlation value (0.221). Additionally, if this item is eliminated it will increase the Cronbach's Alpha value to 0.608. The results of the validity test on the knowledge variables after the knowledge question 14 were eliminated, based on the Pearson test having a significance level of less than 0.05 ( $\mathrm{r}$ values ranging from 0.342 to 0.480 ) and obtaining all values of $r$ count? $\mathrm{r}$ table. With this result, all indicators of attitude are valid. Then, the reliability test obtained the value from Cronbach's Alpha of 0.608.

Table 1: Description and independent test variable result.

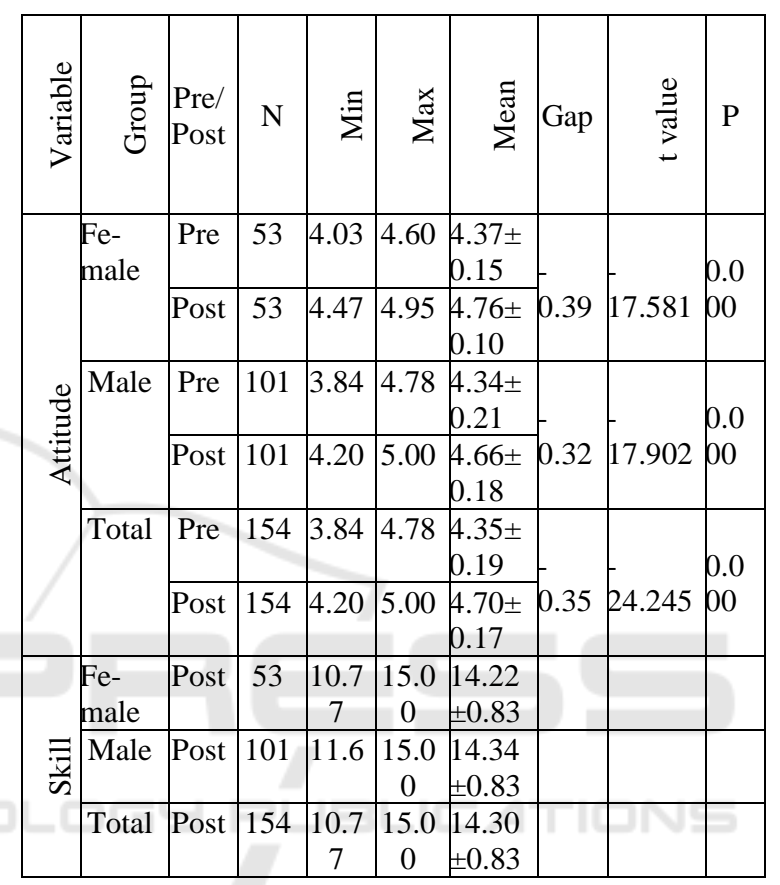

This value is more than 0.5 , and is considered to be reliable. The results of the validity test on the skill variable, based on the Pearson test, has a significance level less than 0.05 ( $\mathrm{r}$ value ranges from 0.183 to 0.472 ) with the $\mathrm{r}$ arithmetic? $\mathrm{r}$ table. With this result, all indicators of attitude are valid. Next, the reliability test obtained Cronbach's Alpha value of 0.556 . This value is more than 0.5 , so the questionnaire is considered reliable and acceptable. Further, confirmed by Cronbach's Alpha test, it was not found that if the item question is removed, this will increase the reliability value of Cronbach's Alpha.

Table 2: Correlation test.

\begin{tabular}{|c|c|c|c|c|}
\hline \multicolumn{2}{|c|}{ Correlation } & \multicolumn{3}{c|}{ Skill } \\
\cline { 3 - 5 } Attitude & Female & Male & Total \\
\hline \multirow{4}{*}{} & Female & $\begin{array}{r}0.327^{*} \\
(0.017)\end{array}$ & & \\
\cline { 2 - 5 } & Male & & $\begin{array}{c}0.316^{* *} \\
(0.001)\end{array}$ & \\
\hline
\end{tabular}




\begin{tabular}{|l|c|c|c|}
\hline & Total & & $\begin{array}{c}0.220 * * \\
(0.006)\end{array}$ \\
\hline
\end{tabular}

** Significantly correlated at 0.01 level ( 2 tailed)

Kolmogorov Smirnov is used to determine from the statistical test that the roots of normality are normal if the significance of the results obtained are more than 0.05. All subsequent data is used to test the data normality. Normal distribution test results are gained, except on the male skill data (Kolmogorov Smimov 0.000 test scores) and overall sample skill (Kolmogorov Smimov 0.000 test scores). Normally distributed data will be tested using abnormally distributed statistics to be tested with nonparametric statistics. Normally distributed data will be tested before and after parametric statistics with a paired sample t test and correlation test using Pearson correlation, while abnormal data is tested using Wilcoxon, and correlation using Spearman correlation.

\section{DISCUSSION}

Information can improve someone's knowledge about problems, which in turn can contribute to behavioral changes. Having knowledge is not always followed by behavioral changes, and such distances exist between them. Ideally, every knowledge improvement is followed by behavioral and attitude changes, but some factors can disrupt that ideal condition (Wik, 1994). Gaining knowledge can be a foundation to behavioral and attitude changes. Repeated strengthening and efforts are needed to make behavior and attitude advance according to the knowledge. Strengthening can be done based on a theory of planned behavior, which encourages everyone around us to learn BLS. BLS should be seen as a good thing based on social norms, so everybody can be motivated if they believe in the norm. Each person's behavioral beliefs will perceive and receive the social acknowledgment that BLS is a positive thing. A combination of 'motivation to comply' and 'behavioral belief' will push everybody to know how to perform BLS properly, which is manifested in people's behavior and confidence in doing BLS (perceived behavioral control). Knowledge, skill, and behavior are important for proper basic life support, which will manifest in people if there is a balanced theory of planned behavior. It cannot be done solely by method, or one person alone. It needs a social effort to motivate and give support to every person to reach the objectives, which is "saving lives for everybody, and by everybody".

\section{CONCLUSIONS}

Our research concludes that mass BLS training undertaken by the method of Faculty of Medicine, Universitas Airlangga, was successful in improving knowledge, skills, and behavior. Repeated efforts should be made to reach our social objectives. Our kind of method in training for BLS should be tried and tested in another population, making it into a better method for the future.

\section{REFERENCES}

Committee E., Subcommittees and Task Forces and the American Heart Association. American Heart Association Guidelines for Cardiopulmonary Resuscitation and Emergency Cardiovascular Care. Circulation. 2005;112(24 Suppl):1-203.

Departemen Kesehatan, 2006. Pharmaceutical care untuk pasien penyakit jantung

Hinton, P., Brownlow, C, B, McMurray, I., 2004. SPSS Explained. New York: 10. Spehr K, Curnow R. 2011. Are Your Objectives Really About Behaviour Change? Or coroner: Fokus sindrom coroner akut. Thttp//circ.ahajournals.org/content/129/3/e28]

Routledge Inc.

Meaney, P-A, Bobrow, B.J., Mancini, M.E., Christenson, J, de Caen, A.R., Bhanji, F. et al. Cardiopulmonary Res Outcomes Both Inside and Outside the Hospital: A Consensus Statement from the American Heart Association. Circulation. 2013 Jul 23:128(4):417-35 Wik, L., Steen, P.A, Bircher, N.G. Quality of Bystander Cardiopulmonary Resuscitation Influences Outcome After Prehospital Cardiac Arrest. Resuscitation. 1994 Dec; 28(3):195-203. Uscitation Quality: [corrected] Improving Cardiac Resuscitation

Nichol, G., Aufderheide, T.P., Eigel, B., Neumar, R.W., Lurie, K.G., Bufalino, V.J., et al, Regional Systems of Care for Out-Of Hospital Cardiac Arrest: A Policy Statement From The American Heart Association. Circulation 2010;121:709-29. Sans, S., Kesteloot, H. \& Kromhout, D. The Burden Of Cardiovascular Diseases Mortality

Philippon, A.L., Bokobza, J., Pernet, J., Medical Students Teach Basic Life Support to Non-Medical Students: A Pilot Study. Resuscitation. 2013: e135-e136

Sans, S.M., Kesteloot, H. \& Kromhout, D. The Burden of Cardiovascular Disease Mortality in Europe. Task Force of the European Society of Cardiology on Cardiovascular Mortality and Morbidity Statistics in Europe. Eur Heart J 1997;18:1231-48. 
Spehr K, Curnow R., 2011. Are They Really About Knowledge and Attitudes? http://www.communitychange.com.au/insights-andtools/21-insights-and-tools/improving-yourprogram/are-your-objectives-really-about-behaviourchange/12.html

The American Heart Association Heart Disease and Stroke Statistics, 2014-update, [http//circ.ahajournals.org/content/129/3/e28]

Wik, L., Steen, P.A., Bircher, N.G. Quality of Bystander Cardiopulmonary Resuscitation Influence Outcome after Prehospital Cardiac Arrest. Resuscitation. 1994 Dec; 28(3):195-203. 